Please send trade news information and illustrations to Arveen Bajaj at the $B D J$, Nature Publishing Group, The Macmillan Building, 4-6 Crinan Street, London N1 9XW. Trade news is provided as a service to readers using text and images from the manufacturer, supplier or distributor and does not imply endorsement by the $B D J$. Normal and prudent research should be exercised before purchase or use of any product mentioned.

\section{Touch-less soap dispensers}

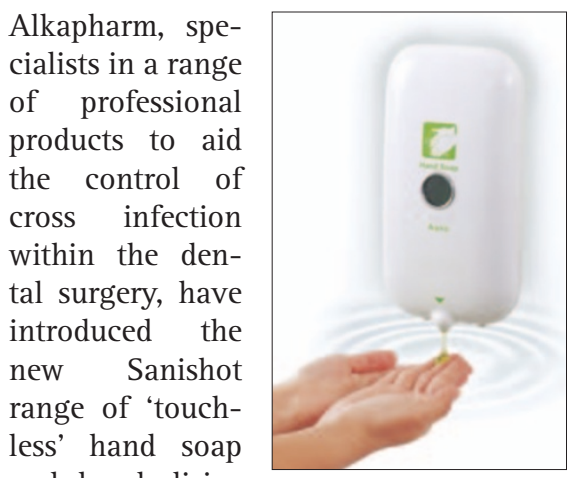
and hand disin-

fectant dispensers. The products detect the presence of hands then automatically dispense the optimum amount of hand soap or disinfectant into the hands. For information visit www.alkapharm.co.uk.

Reader response number 51

\section{Single use drills}

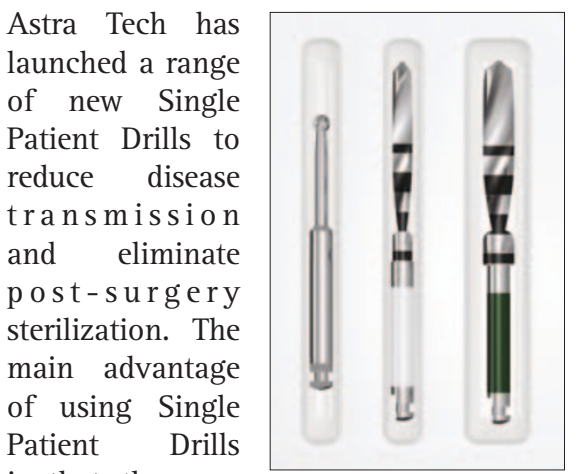

is that they are

sterile and disposable for the added convenience of safeguarding against potential cross contamination during dental treatment. They have a colour coded plastic sleeve, pilot and cortical drills in two lengths, the same tip height on twist drills and time and money savings as there is no cleaning and sterilization to do. These sharp, sterile Single Patient Drills are available in kits with Guided drill, Twist drill 2.0, Twist Drill 3.2 in long or short drills and all other drills come in single-pack. Reader response number 52

\section{In-depth 3D images}

Imtec Imaging has launched the Iluma Ultra Cone Beam CT Scanner. Ultra cone beam CT technology is capable of recreating in-depth 3D images and the company claims that this imaging tool will provide the capability of speeding up the diagnosis process and overseeing treatment from start to finish.

Upright patient positioning is comfortable for patients and the scanner uses minimal physical office space. Placing a patient within the machine is extremely simple; the process of capturing the images desired is effortless for both the patient and the clinician. The entire scan process requires 20 to 40 seconds, so the patient is not confined for any unpleasant length of time. The clinician can begin examining the images and determine a course of treatment without having to schedule many additional consultations with the patient.

The Iluma's software package includes

\section{Integrated intraoral} \section{cameras}

The new Sopro 595 and 717 intraoral cameras by Acteon integrate seamlessly with the A-dec 500 and Radius delivery systems so that dentists can operate the camera directly from the delivery system while being fully connected to their treatment room computer. As a result, operators can now view and save the image directly into the patient record, reducing clutter, improving efficiency and providing clear and simple communication with patients about recommended treatments.

Both the Sopro 595 and 717 offer easy operation, allowing operators to capture and save images from the delivery system foot control or the SoproTouch sensor on the handpiece. Other features include LED lighting technology, analogue and digital imaging capability and a quick-disconnect design for easy sharing between treatment rooms.

The Sopro 595 weighs under $57 \mathrm{~g}$ and provides reliable LED lighting and

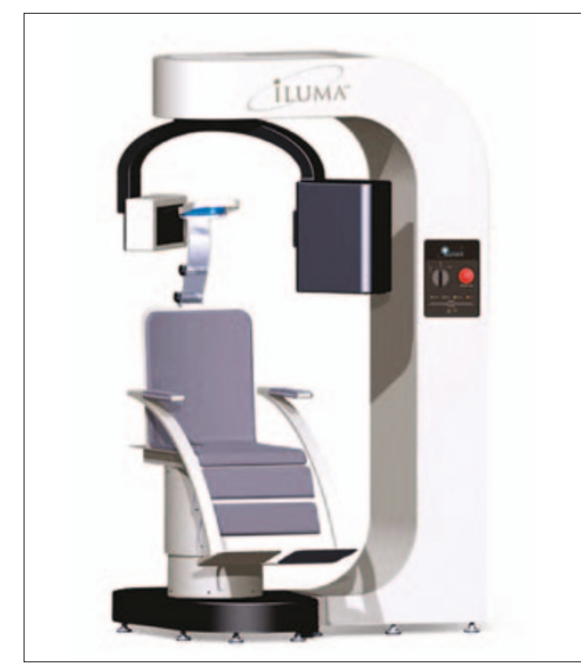

multi-layered facial surface imaging, treatment planning and surgical simulation features. Clinicians can examine each layer of the facial anatomy from the epidermis to the bone.

Reader response number 50

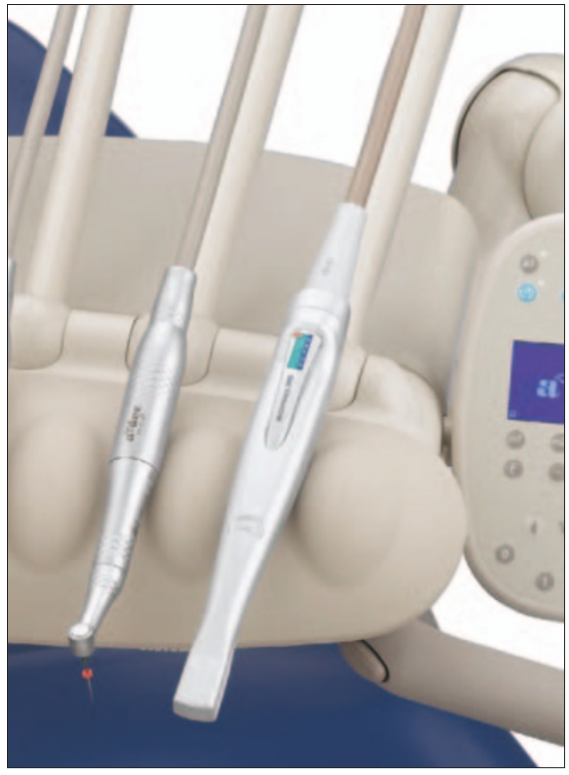

automatic focal adjustments. The image is always sharp with no adjustments or time loss thanks to a large depth of field ( 5 to $30 \mathrm{~mm}$ ) and high quality optics covering a field of $80^{\circ}$.

Reader response number 53 

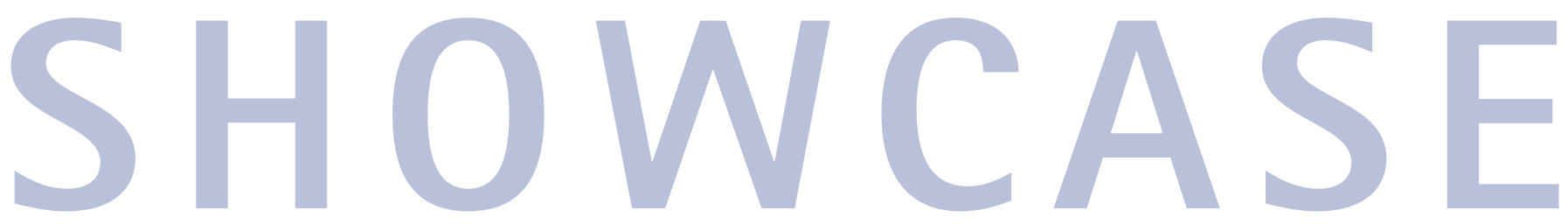

\section{Sitting comfortably}

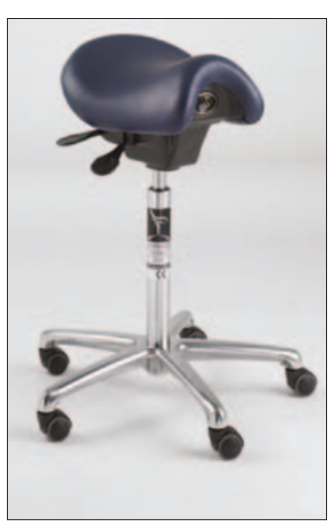

Bambach will be exhibiting on stand B17 at this year's Showcase exhibition.

As well as the standard Bambach Saddle Seat, the new executive model will be on show, which has been developed for the user with a larger frame who requires more support.

Developed by Australian Occupational Therapist, Mary Gale, the Bambach Saddle Seat maintains the pelvis in an anteriorly tilted position without bearing body weight on the knees. The seat is shaped like a horse's saddle and uses the biomechanics of the body to naturally position the spine whilst supporting the pelvis, promoting perfect spinal balance. Dentists seated in this position have complete mobility for seated work and are able to maintain the natural ' $S$ ' shape of the spine, helping to avoid back pain. Even when leaning forward to perform awkward procedures the natural curve of the spine is retained. The Bambach Saddle Seat is endorsed by the Australian Physiotherapy Association to help overcome musculoskeletal problems and has recently been reviewed by Back Care, the national charity for back pain in the UK (www.bambach.co.uk/pdf/talk backarticle.pdf).

Ongoing research is being undertaken by the University of Birmingham, Health Sciences Department in conjunction with the Dental School into the seat and its effects and recent results from the research were published in the International Journal of Therapy and Rehabilitation (www. bambach.co.uk/pdf/universityofbirminghamresearch.pdf).

Reader response number 55

\section{Low abrasion}

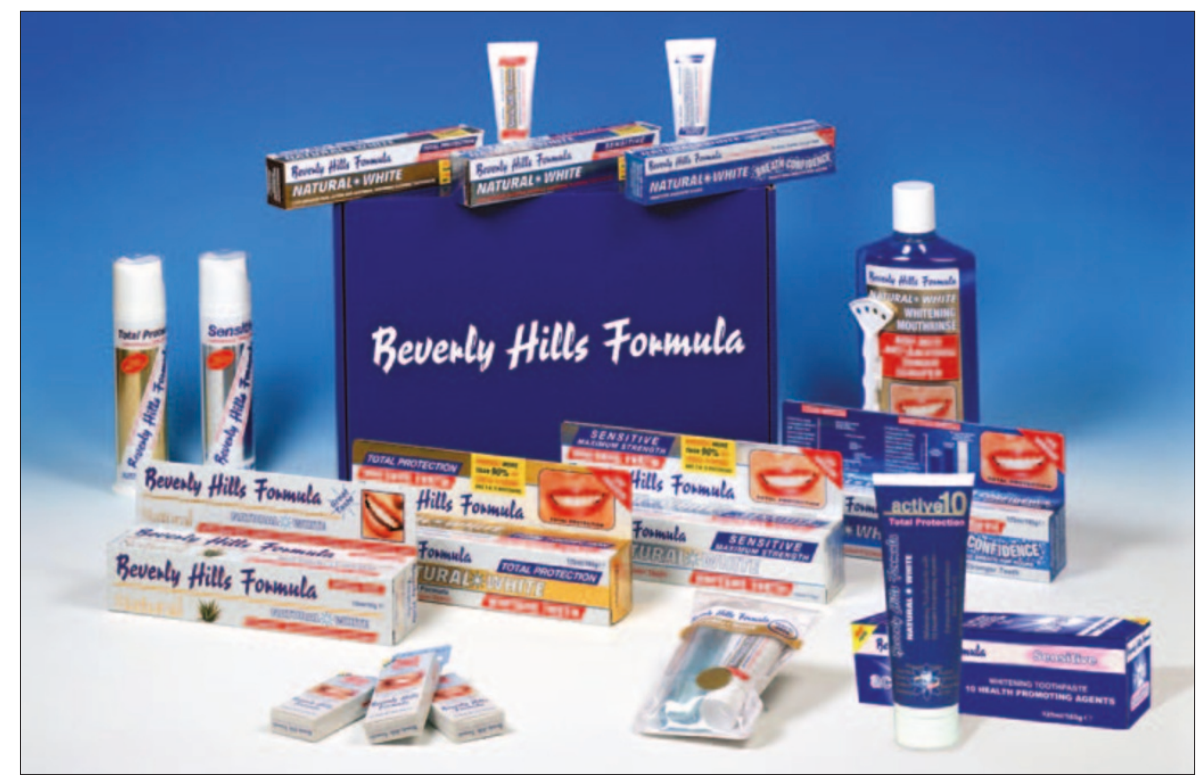

You can find the Beverly Hills Formula at stand number H21 at this year's Showcase exhibition. The Beverly Hills Formula range aims to provide innovative, high quality, niche products in the oral hygiene market. The company claims that its Formula Toothpaste can remove tooth staining and offers maximum whitening power, while maintaining extremely low abrasion. The Total Protection has a dual action anti-bacterial formula to help fight plaque, tooth decay and bad breath. For those suffering from tooth sensitivity, Beverly Hills Formula Sensitive toothpaste offers fast acting, long-lasting protection. Breath Confidence toothpaste has been formulated to fight bad breath for hours and Beverly Hills Formula Natural contains herbal extracts for natural protection with no artificial colouring or flavours. Lastly, Purity Laboratories has recently launched Beverly Hills Formula Active10 (Total Protection and Sensitive), with ten added health promoting agents.

Reader response number 54

\section{Planning for perfection}

A-dec is inviting visitors to Showcase to visit stand $\mathrm{MO} 2$ and share its vision of 'Planning for Perfection'. Those considering a new surgery layout or an upgrade to equipment may want to see the six fully functioning treatment bays featuring the A-dec 500 range; the most recent side and 12 o'clock delivery options and a comprehensive array of the latest range of Adec cabinetry. Also featured this year will be the new Infection Control Centre - a central sterilisation concept pioneered in America and soon to be introduced to the UK market.

Reader response number 56

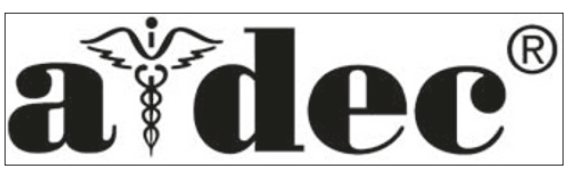




\section{London Dental Showcase 2006}

The BTDA London Dental Showcase is to take place at the ExCeL London, 5-7 0ctober. You can register in advance for your complimentary ticket by visiting www. dentalshowcase.com or calling the telephone hotline 01494 729959. Advance registration closes 30 September 2006. Registration on the day is $€ 10$ per person and tickets are valid for all three days but please remember to take it with you!

Visitors are welcome to bring children with them. However, there are no crèche facilities. Manufacturers, wholesalers, retailers and distributors of products and services to the dental industry exhibit at Showcase. Equipment, sundries, new technologies and literature are all on display at

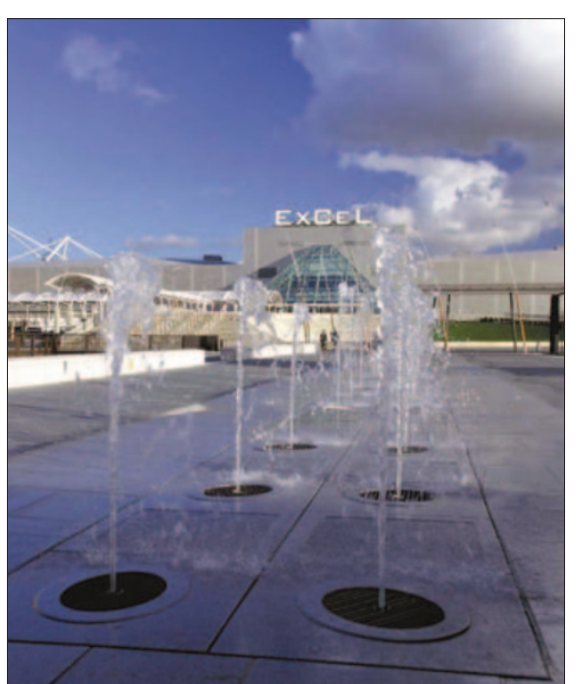

the event and special Showcase offers are available to visitors.

Reader response number 57

\section{Disposable syringe tips}

Special offers and demonstrations are available at the Astek Innovations Ltd stand at S14. They include Pro-Tip Plus, which incorporates separate air and water channels to ensure dry air every time and uniquely locks onto the 3-in-1 syringe so it cannot come off. Converters are available for most 3-in-1 syringes and are free of charge with your first purchase of Pro-Tip Plus (RRSP Ł27.50 per bag of 250 tips). Also on offer is the Alma range of dental prosthetics devices and the Pegasus range of dental consumables. The Alma Range includes Alma Denture Gauge, Alma Bite Gauge, Alma Bite Plane, Alma Wax Tray and the new Alma Alginate Syringe.

Reader response number 58

\section{Become Principal of your own practice}

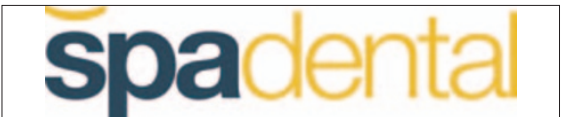

Spa Dental provides ambitious dentists with an opportunity to become principals and to run their own practices. In addition to increased earnings, they will enjoy the benefits of full operational and clinical independence, a full interest in the goodwill growth and will receive a total support package that maximises efficiency

\section{Reaching deeper}

Enlighten's Deep Bleach Protocol claims to whiten any patients' teeth to B1 and beyond, irrelevant of the starting shade. The key difference is that very low concentration gels can be used due to the system's ability to increase the tooth's permeability and go deeper in. The system achieves this without the need for whitening lamps, high concentration gels or gingival protection. Enlighten claim that tetracycline stained teeth can be whitened predictably for the first time using their new super sealed and reduces costs. Any dentist who may currently be an associate in a practice or corporate, returning after a career break, leaving military service or otherwise have past experience in the UK will be warmly welcomed on stand H19 - to meet existing Spa Principals whose practices are now operating successfully. Spa Dental is also looking to acquire high quality dental practices across England and Wales for its principals.

Reader response number 59

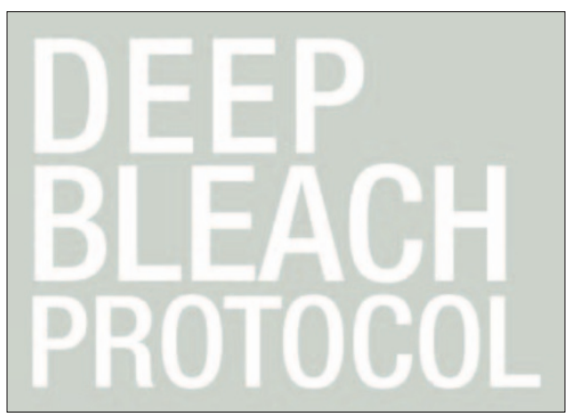

whitening trays followed by a simple in-office procedure.

Reader response number 60 


\section{Test a treatment centre}

Dental equipment manufacturer Takara Belmont will once again exhibit its entire product range on stand F07 at Showcase

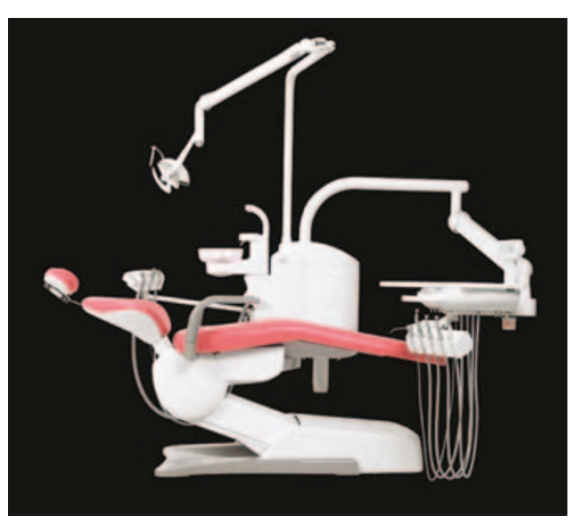

this year. Visitors will be able examine and test Takara Belmont's treatment centres, lights and the new Phot-XII x-ray. Belmont technical, sales and surgery design staff will be on hand to provide detailed information and advice on the equipment, planning and installation while the dental equipment on show will also include the Clesta II, the SP Cleo and the Voyager.

The SP-Cleo dental chair provides patient comfort and the unique Belmont 'folding leg', offers easy access for patients of any age, from the front or either side of the chair, gives treatment staff the room to work freely and enables face to face consultation for a more personal approach. Reader response number $\mathbf{6 1}$

\section{Bespoke surgery service}

Admor's new consultancy service dedicated to practice interiors, branding, merchandising and retailing, 'Admor Design Et Marketing,' will be on stand G11 at this year's Showcase exhibition.

Admor's creative design team will use its skill and knowledge of the potentials

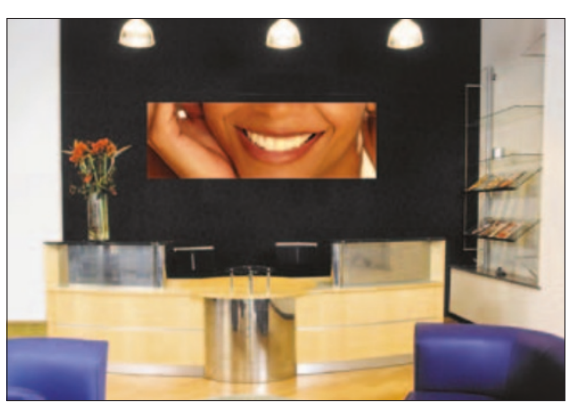

\section{New mouthwash}

Spanish company Dentaid, manufacturer of oral health products, is to launch the chlorhexidine based Perio.Aid mouthwash and Halita 24 hour fresh breath spray via Dent-0-Care Ltd.

Perio.Aid's alcohol free, oral antiseptic formula contains $0.12 \%$ chlorhexidine (CHX) and 0.05\% cetyl pyridinium chloride(CPC) is as efficacious as a 0.20\% CHX solution with alcohol, though with reduced unpleasant subjective side effects.

Halita 24 hour fresh breath spray contains CHX, CPC and Zinc. Scientifically developed to control oral halitosis in the oral cavity, each bottle advises for use as part of a thorough oral hygiene routine. Each box of 12 converts to a point of sale counter dispenser. You can pick up samples of Dentaid products from stand N16 including Interprox Plus interdental of space, structure, materials, textures and colours to transform the interior and exterior of your practice, while Admor's graphic designers can create corporate identities, marketing material, brochures and websites.

To celebrate the new Autumn Interiors Directory, Admor will present a brand new Tub Chair to the winner of a daily draw. All you have to do to enter is visit the stand (no purchase needed). The 2006 Autumn Interiors Directory features many new products, including modular reception desk systems, seating, children's reception products, storage solutions, directory signs, promotional and decorative banners and a $21^{\text {st }}$ Century art collection.

Reader response number 62

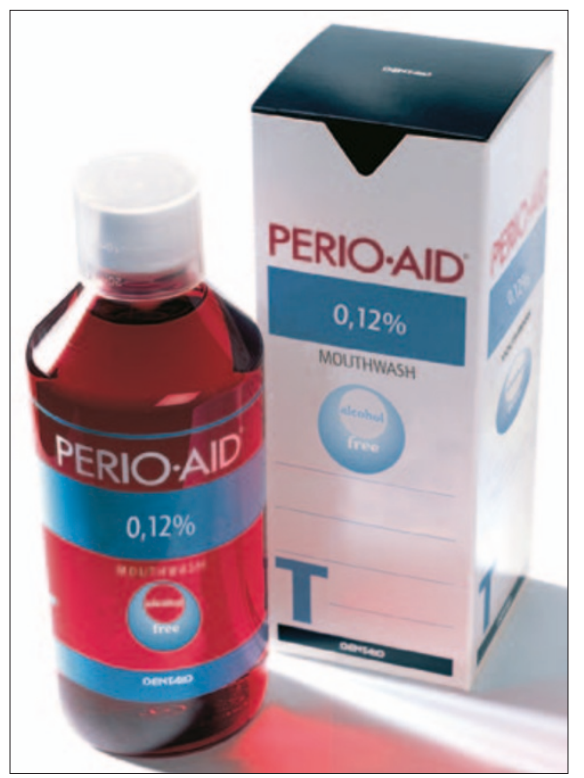

brushes and the Halita tongue cleaner. Reader response number 64

\section{Modern dental style}

German manufacturers Sirona will have a major presence at the London Dental Showcase Exhibition through its general dealers Minerva Dental stands E11/F06, Henry Schein F04, and Sident Dental Systems stand F03. With its theme this year being 'Passion for Dentistry', its Cerec product range for clinicians will be presented by specialist companies Ceramic Systems at stand F02 and Sirona Dental Systems Ltd at stand R02. Specific inLab and inEos laboratory applications will be demonstrated by Panadent on stand L08.

The very latest in Sirona solutions will be displayed and demonstrated enabling exhibition delegates to appreciate modern dental style, functionality and integration technology being put into practice.

Reader response number 63

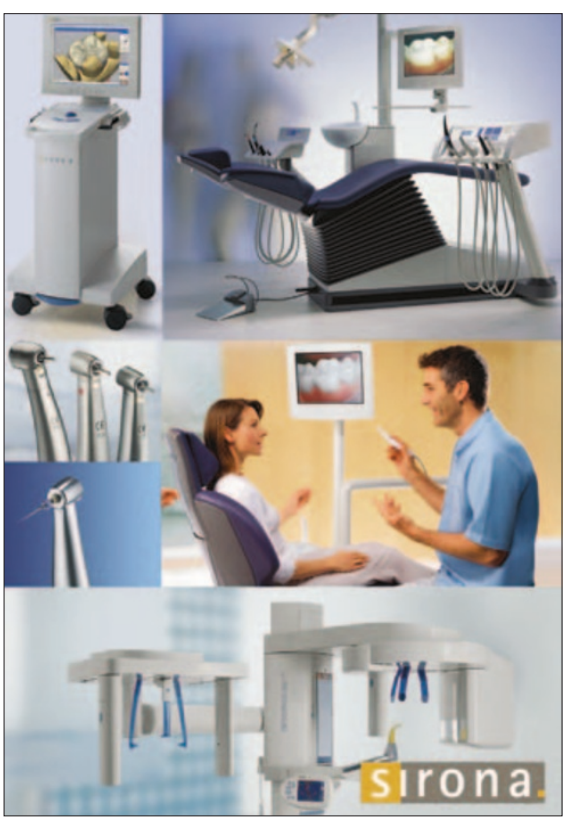

\section{New steriliser launched}

Come to stand M09 at Showcase to find out about the new Lisa 517 steriliser. It has an ECO$B$ cycle that will process small loads in just 20 minutes and instruments come out dry and ready for use or storage. As well as being the manufacturer of Lisa 517, W\&H is known for the design and manufacture of dental handpieces, which you can try for yourself on the stand.

Reader response number 65 


\section{See the difference}

Evident invites all attendees at Dental Showcase to visit them on Stand E01 and take the opportunity to see and experience their wide range of products. You can see the difference that Evident's range of Orascoptic loupes make to your whole

\section{Fvident expanding horizons}

\section{True to life denture}

Myerson's portfolio includes Myerson Special teeth which offer characterising features helping to achieve a more natural 'True to Life' denture and Renamel Microfill, with its wide colour range that simulates a natural appearance, opacity, handling, and long-term wear-resistance.

Myerson's two home whitening systems offer you the choice of either 9\% or 14\% hydrogen peroxide, for personal preference and Bravó's 9\% hydrogen peroxide formula, which does not require refrigeration. The half-hour patient wear time encourages compliance leading to predictable results. The new Perfect-REV home tooth whitening treatment delivers optimal whitening in just 15 minutes, once a day. This unique $14 \%$ hydrogen peroxide, two-step home whitening treatment is water based to rehydrate the teeth as it whitens whilst at the same time preventing tooth sensitivity. This is followed by range of vision by using them in the 'surgery setup' complete with phantom heads.

You can also seat yourself at one of Evident's range of DynamoStol ergonomic stools which automatically correct your sitting position, enabling you to achieve perfect balance no matter what height you may be working at. Evident will also be demonstrating their new range of consumable products including the Prelude Bonding System, flowable composites, Contact Matrix and the unique Contact Wedge System.

Reader response number 66

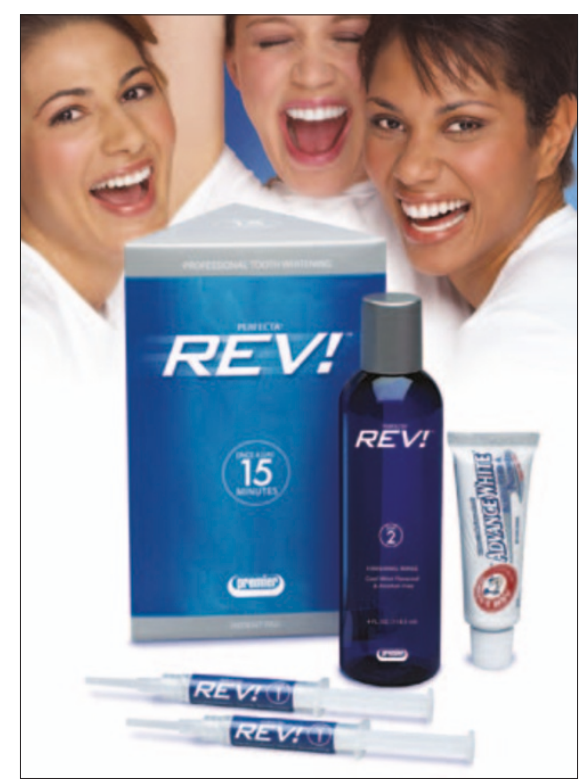

a patient rinse that further enhances the whitening.

Reader response number 67

\section{Healthy mouth, healthy body}

Philips Oral Healthcare is inviting delegates to the British Dental Trade Association Dental Showcase to 'zone out' on its stand at S13. Part of the multizoned stand will be focusing on a "healthy mouth, healthy body' because there is now a gathering body of evidence that connects periodontal disease in the mouth with overall health. As a result, Philips Oral Healthcare has made the links between oral health and systemic health one of its main campaigning platforms for 2006 and is focusing on implications of periodontal disease in coronary heart disease, diabetes and premature low birth weight babies. There will be a variety of health-orientated demonstrations timed throughout the show, and there will be the opportunity for visitors to take part in a unique Sonicare brushing experience with the new Sonicare Elite 9000. In return they will be given the new mini-brush head to take away with them.

Reader response number 70

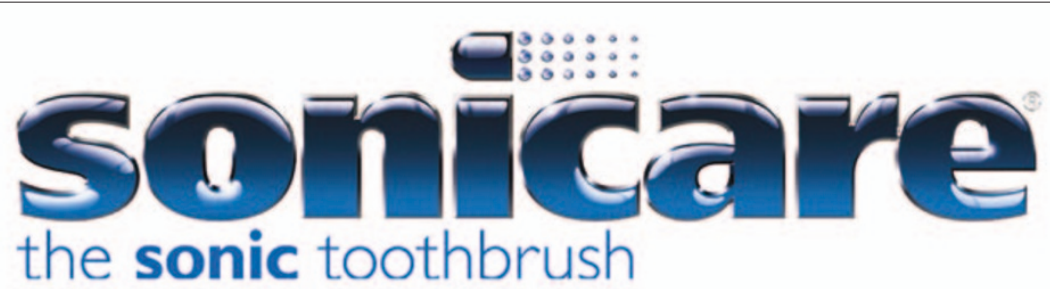

Chair with unique tilt feature

There will be a selection from the latest range of DentalEZ equipment and Star Dental handpieces from the DentalEZ Group at stand U02. On display will be the $\mathrm{J} / \mathrm{V}$ Generation chair which has a unique tilt feature and Ultra Leather upholstery offering patient comfort. To complete the package the company offers the Galaxy chair mounted unit and Lumina light with infra red hands free on/off control.

Star Dental will include the latest range of Solara Lube Free handpieces offering high power (18 watts) and lightweight titanium construction. Solara is available with standard or small/midi head size to fit to Star or Multiflex/Kavo couplings. Special show offers will also be available. Reader response number 68

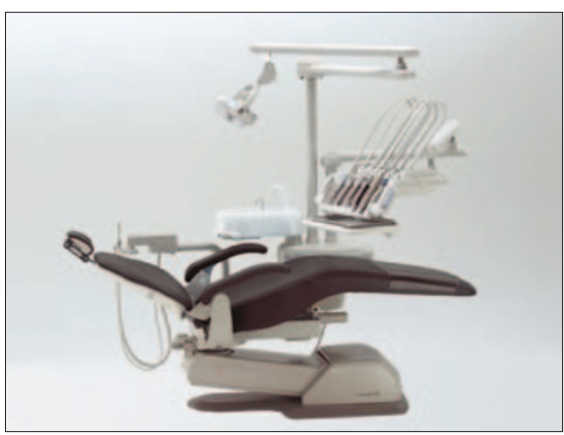

\section{Mail order products}

Mail order dental supplier Kent Express stocks over 20,000 products from a number of manufacturers and compatible products from its own brand portfolio.

Kent Express, on Stand R8-09, will be presenting promotions, as well as many more offers on dental sundries, small equipment and the chance to try garments from its range of Hejco clothing.

Reader response number 69

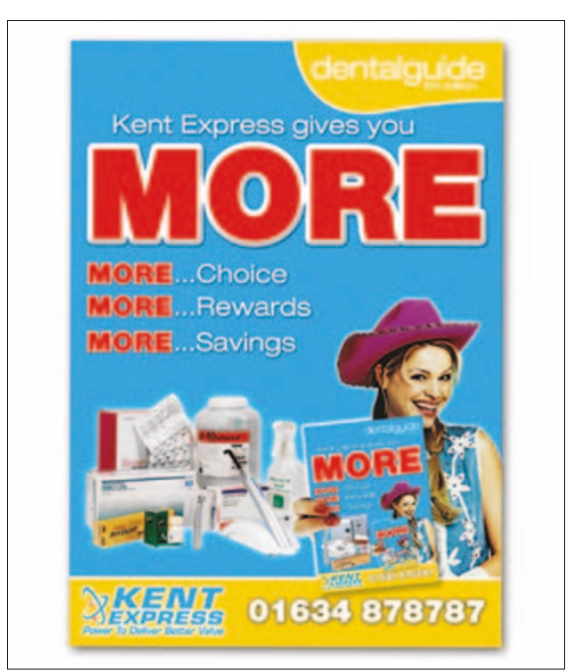




\section{Endodontic solutions}

Quality Endodontic Distributors Limited will be displaying their full endodontic range on stand $\mathrm{B} 18$, including the latest models of the Obtura heated GP system. Other pieces of endodontic equipment on display include the Root ZX apex locator, WAMkey and WAM'X, MTA-Angelus and the MAP system, which together form a first aid kit for endodontics. They will also be showing various endodontic electric motors including DentaPort and the latest generation P5 Newtron, an endodontic ultrasonic machine.

QED's own branded instruments will be on display, including sterile blister packed SteriFiles and triniti sterile nickel titanium rotary instruments, ideally suited to practitioners working within the NHS.

Reader response number 72

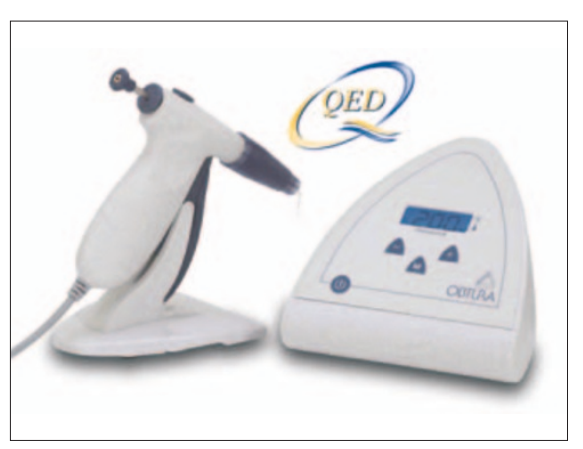

\section{Patient loans}

All dentists and practice managers are invited to visit 3 dee loans to discover how to strengthen your practice cashflow and increase acceptance of treatment plans by helping patients to have the treatment you recommend or the aesthetics they desire.

For the patient, a flexible 3dee loan can pay for treatment costs from £250 to $£ 25,000$ over six to sixty months on an interest-free option or at very sensible and affordable interest rates. The process is simple, only basic, non-intrusive information is required and 3dee provide a rapid response, so there is no delay in the start of treatment.

For the practice there is a real bonus in the fact that a 3 dee patient loan will be paid to the practice, in advance, irrespective of the amount, at the start of the treatment.

For more information visit stand E08B. Reader response number 74

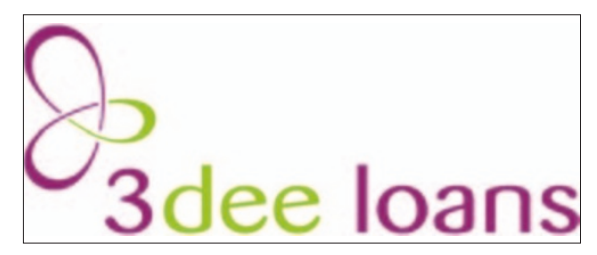

\section{Interactive demonstrations}

Dentsply on stand M6, M7 and M8 at Showcase will feature the ProTaper Universal, Oraqix, Aquasil Ultra Digit, Xeno III Unit Dose, SmartliteTM PS Sunset Version, Xp Bond and SenseusTM as well as other products.

In addition a large Dentsply team will attend the Showcase to present interactive demonstrations and to share with visitors their extensive knowledge of its products, industry best practice and working procedures.

You can visit the stand and take advan-

\section{Magnification systems}

Nuview on stand G08 is the UK supplier of the Carl Zeiss range of magnification and illumination systems, and will exhibit the entire range of these sight-enhancing instruments at the show.

Carl Zeiss systems offer enhanced visual acuity during intricate dental procedures to facilitate, expedite and enhance treatment. Nuview consultants will be present at the Showcase to advise visitors on the most appropriate loupes to meet their specific needs.

Carl Zeiss' binocular magnifying devices provide uncompromised, edge-to-edge clarity of the magnified field of view during dental procedures. They are available in nine different working distances and offer a choice of eleven degrees of magnification, from x 3.2 to $\times 8$.

The OPMI pico is a microscope which

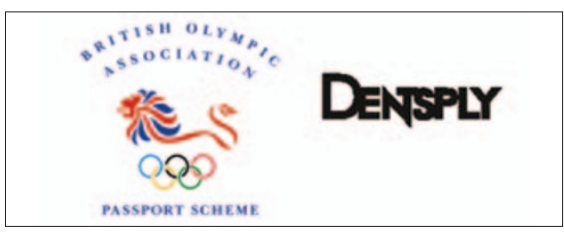

tage of promotional offers on a wide range of Dentsply products, and at the same time enter the its exhibition competition with the prize of a trip to Universal Studios, Florida, USA.

Reader response number 71

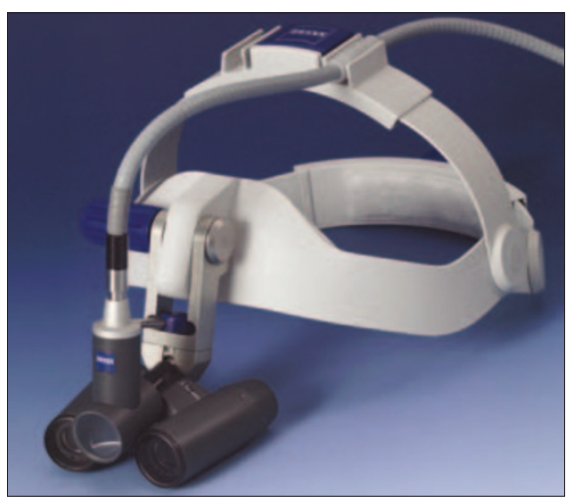

offers magnification and illumination technology developed exclusively for use in dentistry, affording dentists a variety of options to assist in their daily examinations and microsurgical techniques.

Reader response number 73

\section{Microhybrid composite restorative}

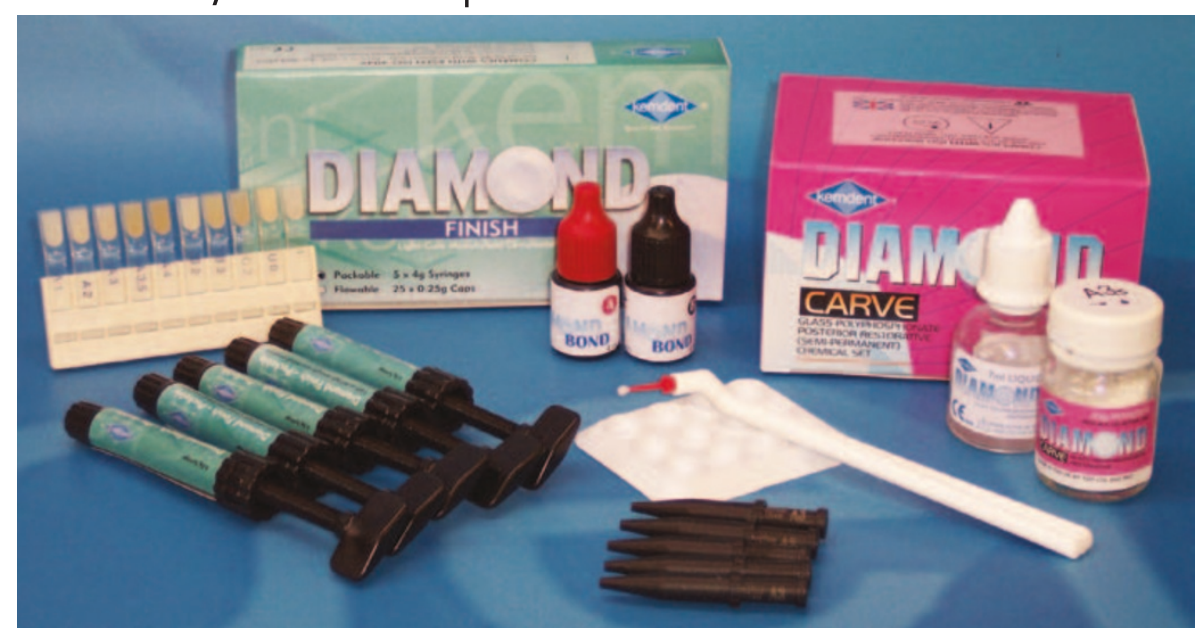

Kemdent on stand E10 will display its new products, including the Diamond Finish, microhybrid composite restorative and Diamond Bond, a bonding, self-etching adhesive.

Diamond Bond enables dentists to combine the advantages of Diamond Carve GIC with aesthetic benefits offered by the new Diamond Finish composite technology in a single procedure.

Reader response number 75 


\section{Surgery equipment and design}

Those looking for chairs, cabinetry or digital imaging equipment at this year's exhibition should visit Clark Dental on stand L03. Two surgeries are on display, one with the A-dec 12 o'clock delivery system and new A-dec slimline cabinetry, and the other with an A-dec unit and cabinetry from the ultra-modern Edarredo range.

Razor-sharp imagery produced by the Schick Digital Imaging System will be on display, which includes the Schick CDR Wireless for intraoral $\mathrm{x}$-ray and the all digital' Schick CDRPanX with new cepha-

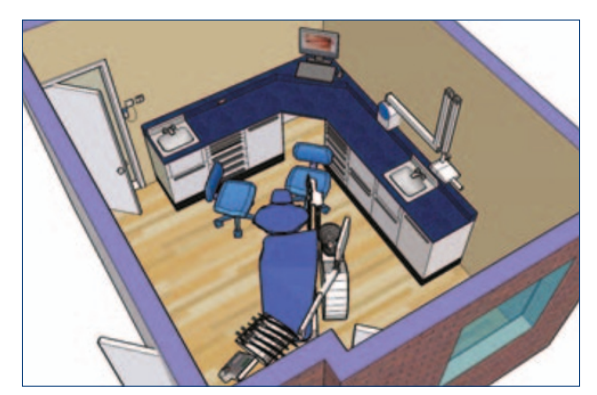

lometric attachment for panoramic. Reader response number 76

\section{Specialists in oral hygiene}

Molar Ltd has been committed to bringing quality products, innovation and variety in oral care to UK dental professionals for almost a decade. Molar's comprehensive range includes market leading products including TePe, ProDen PlaqueOff, bioXtra, TongueDetox and QuitStics.
For the 2006 BDTA Molar are bringing the profession new, innovative and never seen before products. Molar's launch will take place at stand G16 so visitors can come and get involved in the pink initiative.

Reader response number 78

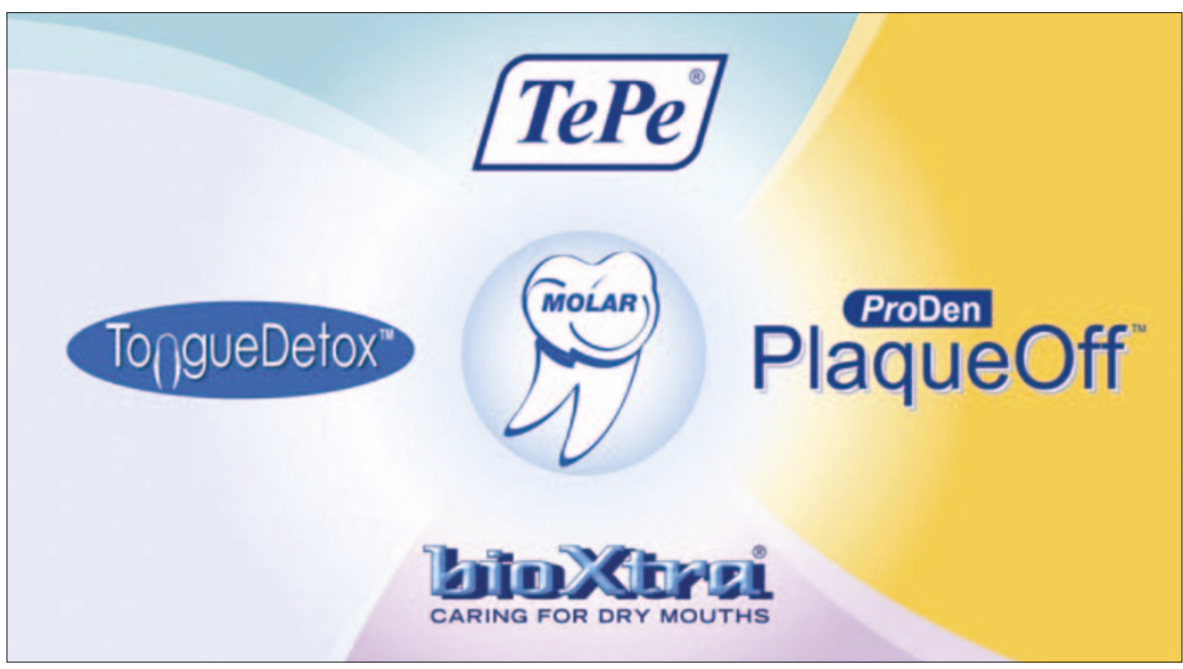

\section{Danish design}

Visitors to Stand N04 will see the latest in Danish design, Heka Dental's intuitive UnicLine equipment. One of its design concepts places all the buttons and functions in one location exactly where you expect to find them. This means operators can keep focused on their working area.

Anyone ordering a UnicLine Treatment Centre, before 1 December 2006, can receive a free trip to "Wonderful Copenhagen" to design their own bespoke unit and visit the Tivoli Christmas Market. Visitors to the stand will also see Climo cabinetry, available in prestige standard or individually designed presentations. Climo offer a full-service from 3D CAD visual design to final set-up and installation.

Reader response number $\mathbf{8 0}$

\section{Anti-snoring appliance}

Distar, manufacturer of Adjustable TheraSnore anti-snoring appliance has recently announced the product is now available in different sizes. The Adjustable TheraSnore treats mild to moderate sleep apnea as well as simple snoring. The new sizes will still be fitted in the surgery in 30 minutes or less without the need of any models, impressions or laboratories and are still adjustable in precise $1.5 \mathrm{~mm}$ increments with out the need to refit the appliance. Distar will be exhibiting at stand C13.

Reader response number 77

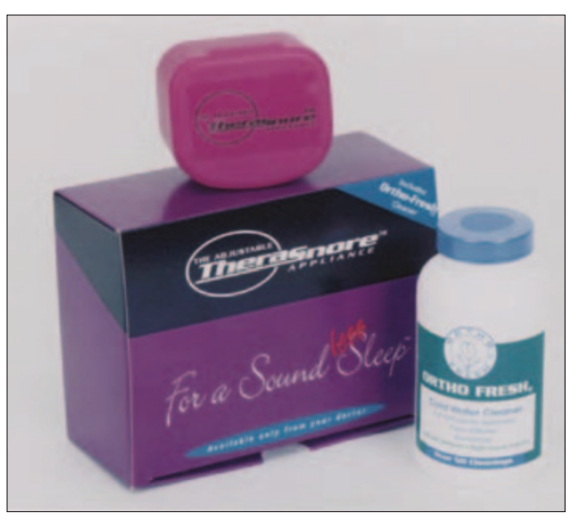

\section{Infection control}

\section{range}

SciCan is a manufacturer of healthcare products such as the Statim S Cycle Cassette Autoclave and includes instrument washers and washer/disinfectors, autoclaves and sterilisation accessories.

Sterilisation in a benchtop Statim $2000 \mathrm{~S}$ autoclave takes just eight minutes to complete for regular loads. It complies with the requirements of the latest standards for the sterilisation of hollow or solid instruments whether or not these are bagged prior to sterilisation.

SciCan will introduce two new washer disinfectors to UK dentists at Dental Showcase; the tabletop Hydrim C51wd and the larger under the bench Hydrim M2. Both units automatically wash, rinse, disinfect and dry stainless steel dental instruments at the touch of a button. To find out more, visit stand P04.

Reader response number 79

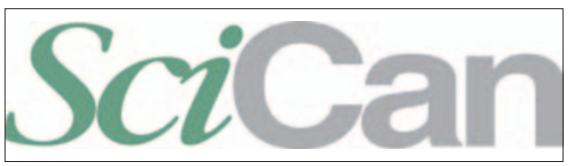

